\title{
A speed-of-play limit reduces gambling expenditure in an online roulette game: Results of an online experiment
}

\author{
Philip W.S. Newall ${ }^{\text {a, }}$, Leonardo Weiss-Cohen ${ }^{\text {b, }}{ }^{\text {, Henrik Singmann }}{ }^{\mathrm{d}}$, W. Paul Boyce ${ }^{\mathrm{e}}$, \\ Lukasz Walasek $^{\mathrm{f}}$, Matthew J. Rockloff ${ }^{g}$ \\ ${ }^{a}$ Experimental Gambling Research Laboratory, School of Health, Medical and Applied Sciences, CQUniversity, 400 Kent St, Sydney, NSW 2000, Australia \\ ${ }^{\mathrm{b}}$ Leeds University Business School, Maurice Keyworth Building, University of Leeds, Leeds LS2 9JT, United Kingdom \\ ${ }^{\mathrm{c}}$ Department of Psychology, Kingston University, River House, 53-57 High Street, Kingston upon Thames, Surrey KT1 1LQ, United Kingdom \\ d Experimental Psychology, University College London, 26 Bedford Way, London WC1H OAP, United Kingdom \\ e School of Psychology, University of New South Wales, Sydney, NSW 2052, Australia \\ ${ }^{\mathrm{f}}$ Department of Psychology, University of Warwick, Coventry CV4 7AL, United Kingdom \\ ${ }^{\mathrm{g}}$ Experimental Gambling Research Laboratory, School of Human, Medical, and Applied Sciences, CQUniversity, University Drive, Bundaberg, QLD 4670, Australia
}

\section{A R T I C L E I N F O}

\section{Keywords:}

Game speed

Online casinos

Online gambling

Product limitations

Structural characteristics

\begin{abstract}
A B S T R A C T
UK online casino games are presently not subject to any limitations on speed-of-play or stakes. One recent policy proposal is to ensure that no online casino game can be played faster than its in-person equivalent. Another policy proposal is to limit the maximum stakes on online casino games to $£ 2$, to match the current stake limit on electronic gambling machines. This research experimentally investigated the speed-of-play proposal subject to a $£ 2$ stake limit, in an online experiment using incentivized payouts based on $£ 4$ endowments and a commercial online roulette game, which was slowed-down in one condition to enforce a speed-of-play limit of one spin every 60 seconds. UK residents, aged 18 years and over and with experience in playing online roulette $(\mathrm{N}=1,002)$, were recruited from an online crowdsourcing panel. In the slowed-down condition there was a credible reduction in the amount gambled. This effect occurred via a credible reduction in the mean number of spins which outweighed any potential increases in bet sizes. Speed-of-play limits may be effective in reducing gambling expenditure for online roulette.
\end{abstract}

\section{Introduction}

Previous international evidence shows that online gambling is a strong risk factor for problem gambling (Allami et al., 2021). Research has therefore explored how consumer protection measures can contribute to lessening the risks experienced by online gamblers, for example by redesigning online gambling platforms (Behavioural Insights Team, 2021), using personalized messages (Heirene \& Gainsbury, 2021; Wohl, Davis, \& Hollingshead, 2017), or by examining online gambling marketing compliance with regulatory requirements (Rossi, Nairn, Smith, \& Inskip, 2021). As the UK has the world's largest regulated online gambling market (Gambling Commission, 2018), this issue has also been of recent interest in UK policy circles, with a number of proposed changes to online gambling having been recently made (House of Lords, 2020; Noyes \& Shepherd, 2020; Public Accounts Committee, 2020). Other jurisdictions are also considering how to regulate online gambling, with many US states currently increasing the availability of online gambling (Jones, 2021).

One area of policy attention is that UK online casino games are not subject to any limitations on stakes or speed-of-play. Taking an online game of roulette as an example, there are no restrictions on how much money or how fast a person can gamble. The regulator (The Gambling Commission) has recently announced that online slots will be limited to a speed-of-play (the minimum time between any two spins) no faster than 2.5 s from October 2021 (Gambling Commission, 2021). Despite this change, many other online casino products are still without limits on either stakes or speed-of-play. Changes to such "structural characteristics" of gambling games have a potential to reduce gambling expenditure (Cornish, 1978; Landon et al., 2018; Livingstone, Woolley, Zazryn, Bakacs, \& Shami, 2008) and consequently gambling-related harm (Browne et al., 2016; Markham, Young, \& Doran, 2016; Muggleton et al., 2021). Indeed, the maximum stake on another high-risk gambling

\footnotetext{
* Corresponding author.

E-mail address: p.newall@cqu.edu.au (P.W.S. Newall).
} 
product, electronic gambling machines (EGMs), was brought down from $£ 100$ to $£ 2$ in the UK in 2019 , and gambling expenditure on this product subsequently fell by almost $50 \%$ (Witherow, 2020). A similar stake-limit has been proposed for online casino games (Gambling Related Harm All Party Parliamentary Group, 2020), given their analogous nature to electronic gambling machines. Stake-limits, however, might impact gamblers at various wealth levels differently: The long-run losses from $£ 2$ bets could still be harmful to some gamblers of more modest means. And if those $£ 2$ bets can be placed at high speed, then a large amount of money could still be lost. Speed-of-play limits are therefore another structural characteristic worthy of wider consideration, with the recent House of Lords report recommending that "no game can be played quicker online than in a casino, betting shop or bingo hall" (House of Lords, 2020). The present work experimentally investigated the effects of this recommendation on gamblers' behavior using an incentivized and realistic online roulette game.

A recent dataset from UK online casinos shows why consumer protection measures other than stake limits might be worth considering. Most online casino sessions played by UK gamblers are relatively small stakes, with $78 \%$ winning or losing less than $£ 20$, and $93 \%$ of sessions lasting less than an hour (Forrest \& McHale, 2021). According to the authors, "long sessions represent an atypical behaviour" (Forrest \& McHale, 2021) p.32). The relatively small stakes played may be in part due to a skew in play occurring from relatively deprived areas: $21 \%$ of spend came from the most deprived areas of the country, compared to 17\% from the least deprived areas (Forrest \& McHale, 2021).

Previous reviews of the literature have noted the need for more research on speed-of-play limits (Armstrong, Rockloff, Greer, \& Donaldson, 2017; Lawn et al., 2020), with one review emphasizing that much of this literature is limited by small sample sizes and tasks with low ecological validity (Harris \& Griffiths, 2018). Table 1 displays key properties of relevant empirical research on the speed-of-play covered by these three recent reviews. Research has either used simplified gambling tasks (Corr \& Thompson, 2014; Thompson \& Corr, 2013); or simplified slot machine simulators (Chóliz, 2010; Delfabbro, Falzon, \& Ingram, 2005; Harris, Gous, de Wet, \& Griffiths, 2021; Ladouceur \& Sevigny, 2006; Mentzoni, Laberg, Brunborg, Molde, \& Pallesen, 2012; Worhunsky \& Rogers, 2018) with a smaller range of betting options than are available on commercial slot machines (Dixon et al., 2018; Harrigan, MacLaren, Brown, Dixon, \& Livingstone, 2014). Two studies have shown significant effects on gambling behavior from speed-of-play limits in commercial EGMs in laboratory conditions (Linnet, Rømer Thomsen, Møller, \& Callesen, 2010; Loba, Stewart, Klein, \& Blackburn, 2001), while two field studies found no significant effects (Blaszczynski, Sharpe, Walker, Shannon, \& Coughlan, 2005; Sharpe, Walker, Coughlan, Enersen, \& Blaszczynski, 2005). Those two field studies are also the only ones on this list with sample sizes above 100, indicating that these are the only two studies able to reliably detect anything other than large effect sizes with sufficient statistical power (Cohen, 1992).

This highlights that the majority of research investigating speed-ofplay in commercial gambling games has been on EGMs or slots, two gambling formats associated with relatively recent UK consumer protection measures. There is therefore a relative lack of research on other games, such as online roulette. This may be consequential, as different games can have different average speeds, making it difficult to extrapolate findings across games. For example, the majority of EGM and slots studies from Table 1 have a slowest speed condition of around $5 \mathrm{~s}$. However, a re-analysis of previous experimental data using the same commercial online roulette game as the present experiment's control condition (without any speed-of-play limitations) suggested a mean speed-of-play of $21 \mathrm{~s}$, with the fastest participants gambling as often as once every $10 \mathrm{~s}$, which is essentially the speed that the roulette wheel takes to spin (Newall, Weiss-Cohen, Singmann, Walasek, \& Ludvig, 2021). The slower pace of online roulette in comparison to EGMs and slots is one structural difference meaning that research should be cautious with respect to extrapolating findings across different gambling
Table 1

Review of previous quantitative research on speed-of-play limits.

\begin{tabular}{|c|c|c|c|}
\hline Reference & Task & $\begin{array}{l}\text { Sample } \\
\text { size }\end{array}$ & Key finding \\
\hline $\begin{array}{l}\text { (Corr \& } \\
\text { Thompson, } \\
\text { 2014) }\end{array}$ & $\begin{array}{l}\text { Simplified lab } \\
\text { gambling task }\end{array}$ & 42 & $\begin{array}{l}\text { Five-second delay reduced } \\
\text { participants' losses }\end{array}$ \\
\hline $\begin{array}{r}\text { (Thompson \& } \\
\text { Corr, 2013) }\end{array}$ & $\begin{array}{l}\text { Simplified lab } \\
\text { gambling task }\end{array}$ & 81 & $\begin{array}{l}\text { Five-second delay reduced } \\
\text { problem gamblers' excess } \\
\text { losses compared to } \\
\text { recreational gamblers }\end{array}$ \\
\hline $\begin{array}{l}\text { (Mentzoni et al., } \\
\text { 2012) }\end{array}$ & $\begin{array}{l}\text { Single-line slot } \\
\text { machine simulator }\end{array}$ & 62 & $\begin{array}{l}\text { At-risk gamblers bet larger } \\
\text { amounts at a } 0.4 \mathrm{~s} \text { delay than } \\
\text { at } 3 \mathrm{~s}\end{array}$ \\
\hline $\begin{array}{l}\text { (Harris et al., } \\
\text { 2021) }\end{array}$ & $\begin{array}{l}\text { Single-line slot } \\
\text { machine simulator }\end{array}$ & 50 & $\begin{array}{l}\text { Worse performance on a } \\
\text { secondary task at a faster } \\
\text { game speed }\end{array}$ \\
\hline $\begin{array}{l}\text { (Worhunsky \& } \\
\text { Rogers, 2018) }\end{array}$ & $\begin{array}{l}\text { Single-line slot } \\
\text { machine simulator }\end{array}$ & 72 & $\begin{array}{l}\text { Preferred rate of play not } \\
\text { related to problem gambling } \\
\text { severity }\end{array}$ \\
\hline (Chóliz, 2010) & $\begin{array}{l}\text { Single-line slot } \\
\text { machine simulator }\end{array}$ & 10 & $\begin{array}{l}\text { Treatment-seeking problem } \\
\text { gamblers bet fewer times } \\
\text { when the fastest speed-of- } \\
\text { play increased from 2- to 10- } \\
\text { seconds }\end{array}$ \\
\hline $\begin{array}{l}\text { (Ladouceur \& } \\
\quad \text { Sevigny, } \\
\text { 2006) }\end{array}$ & $\begin{array}{l}\text { Single-line slot } \\
\text { machine simulator }\end{array}$ & 43 & $\begin{array}{l}\text { Recreational gamblers bet } \\
\text { fewer times when the fastest } \\
\text { speed-of-play was increased } \\
\text { from 5- to } 15 \text {-seconds }\end{array}$ \\
\hline $\begin{array}{l}\text { (Delfabbro } \\
\text { et al., 2005) }\end{array}$ & $\begin{array}{l}\text { Single- and multi- } \\
\text { line slot machine } \\
\text { simulators }\end{array}$ & 24 & $\begin{array}{l}\text { Gamblers bet fewer times } \\
\text { when the fastest speed-of- } \\
\text { play was increased from 3.5- } \\
\text { to 5-seconds }\end{array}$ \\
\hline $\begin{array}{l}\text { (Loba et al., } \\
\text { 2001) }\end{array}$ & $\begin{array}{l}\text { Laboratory-based } \\
\text { commercial EGM }\end{array}$ & 60 & $\begin{array}{l}\text { Pathological gamblers had } \\
\text { more difficulty than } \\
\text { recreational gamblers in } \\
\text { stopping playing a fast game } \\
\text { with sound effects }\end{array}$ \\
\hline $\begin{array}{l}\text { (Linnet et al., } \\
\text { 2010) }\end{array}$ & $\begin{array}{l}\text { Laboratory-based } \\
\text { commercial EGM }\end{array}$ & 30 & $\begin{array}{l}\text { Increasing the fastest speed- } \\
\text { of-play from } 2 \text { - to } 3 \text {-seconds } \\
\text { reduced time spent } \\
\text { gambling by pathological } \\
\text { and recreational gamblers }\end{array}$ \\
\hline $\begin{array}{l}\text { (Sharpe et al., } \\
\text { 2005) }\end{array}$ & $\begin{array}{l}\text { Field-based } \\
\text { commercial EGM }\end{array}$ & 779 & $\begin{array}{l}\text { Increasing the fastest speed- } \\
\text { of-play from 3.5- to } 5 \text {-sec- } \\
\text { onds had no effect on } \\
\text { gambling behavior }\end{array}$ \\
\hline $\begin{array}{l}\text { (Blaszczynski } \\
\text { et al., 2005) }\end{array}$ & $\begin{array}{l}\text { Field-based } \\
\text { commercial EGM }\end{array}$ & 363 & $\begin{array}{l}\text { Increasing the fastest speed- } \\
\text { of-play from 3.5- to 5-sec- } \\
\text { onds had no effect on self- } \\
\text { reported enjoyment }\end{array}$ \\
\hline
\end{tabular}

games.

\section{Research questions}

The present work therefore experimentally manipulated a speed-ofplay limit on a commercial online roulette game: a background timer enforced a speed-of-play limit of one spin every 60 seconds in the slowed-down condition, which was chosen as being representative of the average speed-of-play in land-based casino roulette (Kilby, Fox, \& Lucas, 2004). Our preregistered hypothesis was that participants would gamble a higher proportion of their overall provided funds in the unrestricted normal-speed game than the slowed-down game, which would in the long-run lead to higher financial losses due to the $2.7 \%$ house edge inherent in European roulette (Grochowski, 2021). However, any alteration of structural characteristics may be ineffective in shaping behavior (Sharpe et al., 2005) or may backfire and have unintended consequences (Harris \& Griffiths, 2018). In the experimental context, the chief potential avenue for backfiring is that participants might bet more per-spin in the slowed-down game. This effect could potentially more than outweigh any reductions in total number of spins played in the slowed-down game. We therefore also planned analyses on the 
effects of the speed-of-play limit on the number of spins and amount bet per-spin in both conditions. Finally, we also conducted some unplanned exploratory analysis on whether the manipulation affected the riskiness of bets chosen, and whether it had effects dependent upon participants' level of problem gambling severity.

\section{Method}

The preregistration document, and experimental materials, data, and analysis scripts can be accessed from the Open Science Repository (OSF) associated with this project (https://osf.io/bavq9/).

\subsection{Ethics}

Previous studies have used gambling tasks with incentivized payouts and a sample of participants from across the range of problem gambling severity (Delfabbro et al., 2005; Linnet et al., 2010). In order to minimize the risk of any potential negative consequences from taking part in this research, the following steps were taken. All participants were informed about the nature of the initial task and the optional roulette game for those who passed that initial task. Help-line information was provided on the information sheet and on the task debrief. Participants were informed that they were not required to gamble and could opt to receive their full endowment without placing any bets (which formed one of the study's dependent measures), and all participants finished the study with more money than they started with. The study received ethical approval from CQUniversity's Ethics Committee (\#22852).

\subsection{Recruitment}

Participants were recruited via the online platform Prolific. The platform provides pre-screener questions, previously asked by Prolific, which can be used to filter the eligibility of participants. Using two such pre-screeners, only participants who (a) reported being resident in the
$\mathrm{UK}$, and (b) having prior experience playing online roulette, were allowed to participate in the study. Furthermore, only individuals aged 18 or above are allowed to use Prolific. Participants were recruited via adverts placed on the platform on 24th and 25th of February 2021, until the preregistered sample size was reached. While a power analysis was not feasible based on the below statistical model, the sample size was chosen to comfortably exceed the sample size used in any previous investigation of speed-of-play limits (see Table 1), and also to exceed the 322 participants per-condition required to detect a small effect size with power $=0.8$ in a traditional ANOVA model (Cohen, 1992).

There were 5,758 eligible participants in the platform, of which a total sample of $\mathrm{N}=1,186$ was recruited. All participants took part in the initial captchas task; $182(15.3 \%)$ typed six or fewer captcha codes correctly and did not take part in the experiment further. The 1,004 participants who passed the captchas phase with seven or more correct captchas were allocated to one of two parallel experimental conditions (normal or slowed-down). The allocation was sequentially-random with constant re-balancing. When the number of participants was the same in the two conditions, a new participant was allocated using a simple computer randomization function, with equal weights (1:1 allocation ratio). Otherwise, if the number of participants in each condition was not the same, a new participant was allocated to the condition with the fewest participants. Two participants from the normal condition were excluded for abandoning the experiment part-way through, for a total final sample of $\mathrm{N}=1,002$ participants, of which 500 were in the normal condition and 502 were in the slowed-down condition (see Fig. 1 for a CONSORT flow chart).

All participants were paid a minimum guaranteed baseline payment of $£ 2.50$. Participants who passed the captchas were provided with a further $£ 4$ to optionally use on the roulette game. These 1,002 participants took an average of $9.3 \mathrm{~min}$ to complete the experiment and ended with an average roulette balance of $£ 4.06$ ( $£ 42.53$ total compensation per-hour pro-rata). Participant demographics, including the distribution of Problem Gambling Severity Scores (PGSI), can be seen in Table 2. Age

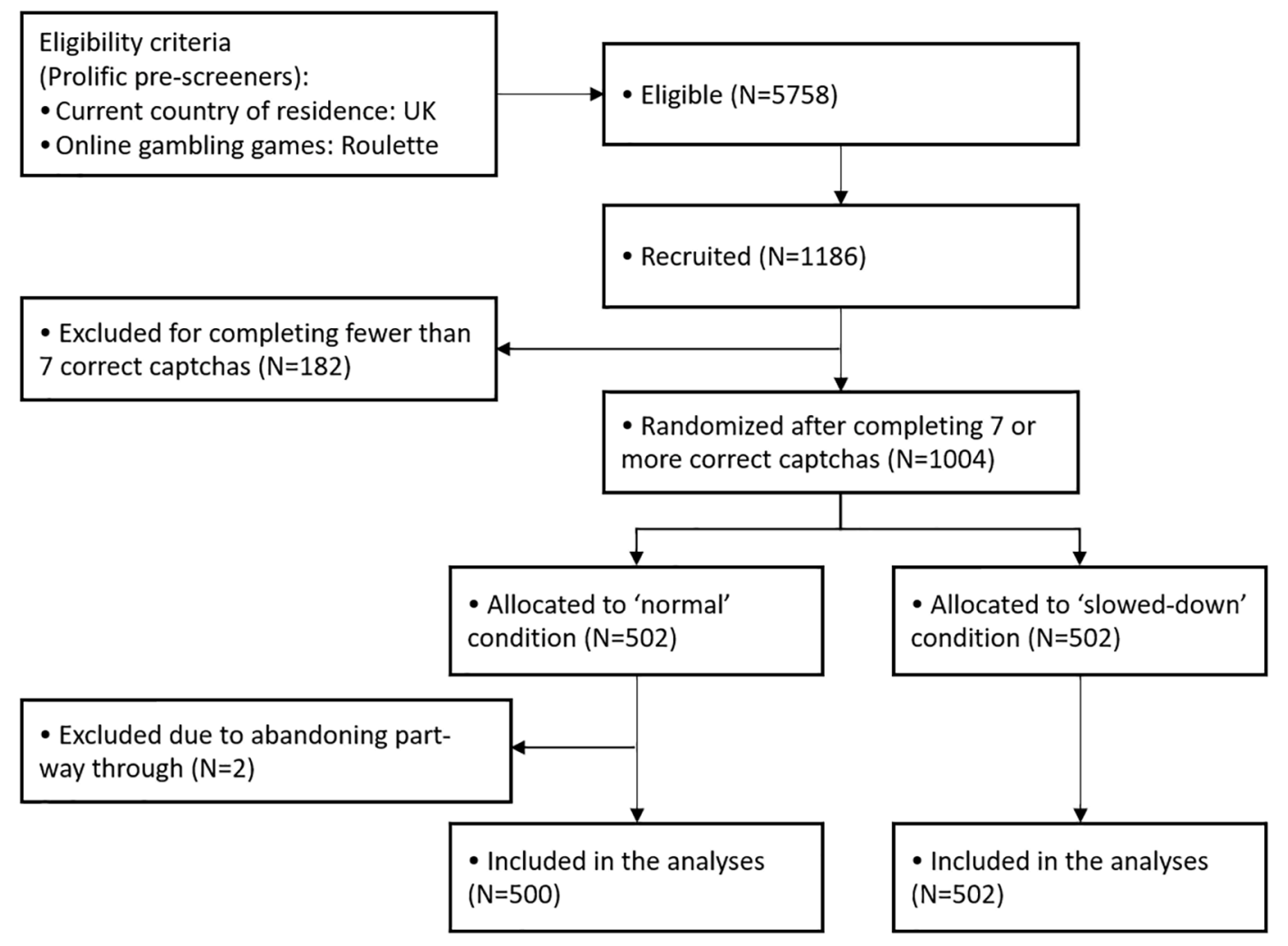

Fig. 1. CONSORT flow chart for the experiment. 
Table 2

Participant demographics.

\begin{tabular}{|c|c|c|c|}
\hline $\begin{array}{l}\mathrm{N}(\%) \\
\text { Except for Age (Mean and } \\
\text { SD) }\end{array}$ & $\begin{array}{l}\text { Normal } \\
N=500\end{array}$ & $\begin{array}{l}\text { Slowed-down } \\
\mathrm{N}=502\end{array}$ & $\begin{array}{l}\text { Total } \\
\mathrm{N}=1002\end{array}$ \\
\hline Age & $\begin{array}{l}M=33.6(S D \\
=9.8)\end{array}$ & $\begin{array}{l}\mathrm{M}=34.4(\mathrm{SD}= \\
10.9)\end{array}$ & $\begin{array}{l}\mathrm{M}=34.0(\mathrm{SD}= \\
10.4)\end{array}$ \\
\hline $\begin{array}{l}\text { Sex }=\text { Female } \\
\text { PGSI (Ferris \& Wynne, } \\
\text { 2001) }\end{array}$ & $167 *(33.4 \%)$ & $173(34.5 \%)$ & $340 *(33.9 \%)$ \\
\hline No risk (0) & $158(31.6 \%)$ & $169(33.7 \%)$ & $327(32.6 \%)$ \\
\hline Low risk (1-2) & $134(26.8 \%)$ & $125(24.9 \%)$ & $259(25.8 \%)$ \\
\hline Moderate risk (3-7) & $153(30.6 \%)$ & $147(29.3 \%)$ & $300(29.9 \%)$ \\
\hline $\begin{array}{l}\text { Problem gambler }(8+) \\
\text { PGSI (Currie, Hodgins, \& } \\
\text { Casey, 2013) }\end{array}$ & $55(11.0 \%)$ & $61(12.2 \%)$ & $116(11.6 \%)$ \\
\hline No risk $(0)$ & $158(31.6 \%)$ & $169(33.7 \%)$ & $327(32.6 \%)$ \\
\hline Low risk (1-4) & $227(45.4 \%)$ & $197(39.2 \%)$ & $424(42.3 \%)$ \\
\hline Moderate risk (5-7) & $60(12.0 \%)$ & $75(14.9 \%)$ & 135 (13.5\%) \\
\hline Problem gambler $(8+)$ & $55(11.0 \%)$ & $61(12.2 \%)$ & $116(11.6 \%)$ \\
\hline
\end{tabular}

Note: $(*)$ one participant in the normal condition did not disclose.

and gender data was collected and provided by Prolific.

\subsection{Design}

Code for a commercial online roulette game ("Roulette Royale") was purchased by us (Codecanyon, n.d.) and its code edited by a professional coder to implement the speed-of-play manipulation.

Our literature search did not find a consensus on the mean speed-ofplay in land-based casino roulette. We found estimates of the mean speed-of-play (the average time between two roulette spins) of $40 \mathrm{~s}$ (Downton \& Holder, 1972), 80 s (Grochowski, 2021), 150 s (Oldman, 1974), and a range of 32 s to 103 s (Kilby et al., 2004). A speed-of-play limit of one spin every 60 seconds was chosen for this experiment's slowed-down condition as a reasonable average of these diverse estimates. These times refer to classic roulette games, where a croupier spins a real ball, rather than innovated electronic casino roulette, where the spinning wheel is digitized (Armstrong, Rockloff, \& Donaldson, 2016).

Participants earned their $£ 4$ gambling endowments by successfully transcribing seven or more out of ten randomly displayed captcha codes, all of which can be viewed at https://osf.io/bavq9/. This initial task therefore screened-out inattentive participants, who did not proceed to the roulette part of the experiment, which online crowdsourcing platforms such as Prolific have been criticized for containing (Pickering \& Blaszczynski, 2021). The initial task is also an example of a "real-effort task" from economics, designed to create a sense of ownership over these endowments, in order to better approximate gambling with one's own money (Erkal, Gangadharan, \& Nikiforakis, 2011).

A $£ 2$ stake limit was used, both to economize on the maximum potential payout and also to match a proposed stake limit for UK online casino games (Gambling Related Harm All Party Parliamentary Group, 2020). Participants would have been moved on from the roulette if they had reached a balance of $£ 105$; although the maximum balance reached at any point was $£ 72$.

Before the roulette game started, participants were shown a page of roulette playing instructions relevant to their experimental condition. Control-condition (normal-speed) participants were told that they could spin the roulette as soon as they liked once they placed any bets on the roulette table. Participants in the slowed-down-condition were told that the speed-of-play limit was one spin every $60 \mathrm{~s}$. While their first spin could be made as soon as the roulette game loaded, further spins had to wait at least $60 \mathrm{~s}$ after the previous spin. During this 60 -second waiting period, bets could be placed on the roulette table, but a greyed-out "wait" button appeared instead of the spin button, which could not be clicked. A spinning wheel appeared next to the "wait" button, indicating the passage of time. Once the waiting period was over, the inactive "wait" button was replaced by an active spin button. Screenshots of the roulette game from both conditions are shown in Fig. 2.

Participants were able to interact with the roulette game for as long as they liked, as long as they still had endowment funds left. There were no minimum or maximum times that they had to play for. Participants completed the PGSI before finishing the experiment. Demographics were automatically collected by Prolific. All payments were made after data collection was complete.

\subsection{Analysis}

The study's aim was to measure the effect of the speed-of-play limit on gambling behavior that was as realistic as possible. Some gambling experiments seek to control extraneous noise by presenting participants with a fixed stream of outcomes (Byrne \& Russell, 2020), or by programming losses after a given number of bets (Rockloff, Donaldson, \& Browne, 2015). However, either of these approaches would have limited the external validity of the findings. It was therefore decided to use fair and random outcomes, as in online roulette. However, this design choice meant a dependent variable was needed that could account for participants' luck. Participants in this experiment actually experienced a small amount of positive luck on average, winning an average of $£ 0.06$ despite the $2.7 \%$ house edge.

We chose a dependent variable called "proportion bet" which scaled participants' total amount bet by the sum of their initial available stake and any winnings from successful bets. This was chosen as a succinct summary of participants' gambling in proportion to the maximum that they could have risked, depending on their luck. This dependent variable was chosen given the large number of betting options in the roulette game, and the large number of betting histories depending on the random outcomes. The variable was defined as:

proportion bet $=$ total amount bet/(initial endowment + gross winnings)

This variable takes a minimum of zero for a participant who bet nothing, and a maximum of one for a participant who bet and lost everything, including any winnings from previous bets. Participants were also able to bet a fraction of their money, therefore potentially leaving the roulette with some other bonus amount. This means that the proportion bet for a participant betting $£ 4$ in total but leaving with a final balance of $£ 4$ was 0.5 (because they must also have won $£ 4$ ); lower than the proportion bet of 1 for a participant who bet $£ 4$ without winning any bets (and leaving with zero). The rationale for this is that a participant betting $£ 4$ but leaving with $£ 4$ chose to gamble less than their theoretical maximum (they could have bet at least $£ 8$ ).

This dependent variable was analyzed with a zero-one-inflated beta regression (ZOIBR) model. A previous experiment with a similar online roulette task suggested that the dependent variable was likely to have peaks around zero (gambling nothing), one (gambling everything), with a broad range of intermediate values, and that the ZOIBR should be able to accurately reflect this pattern of responses (Newall et al., 2021).

We were also interested in how the speed-of-play limit would affect participants' interaction with the roulette game. We therefore planned analyses for two further dependent variables: the number of spins played, and the amount bet per-spin. The speed limit's effect on the number of spins was assessed via a negative binomial model truncated at zero for participants who gambled at least once, since the speed limit's effect on participants' decision to bet at all was assessed via the previous model. The speed limit's effect on average bet size was assessed by a oneinflated beta regression, with the average bet size divided by the maximum potential bet size: two. This is because the average bet size could not be zero but could be as high as two. Thus, this model assessed whether the speed-of-play limit affected participants': probability to always bet the maximum ( $£ 2$ ); and mean bet size, if they did not always bet the maximum.

A Bayesian estimation approach (van de Schoot et al., 2021) was chosen, because for the type of statistical models employed here, 
A)

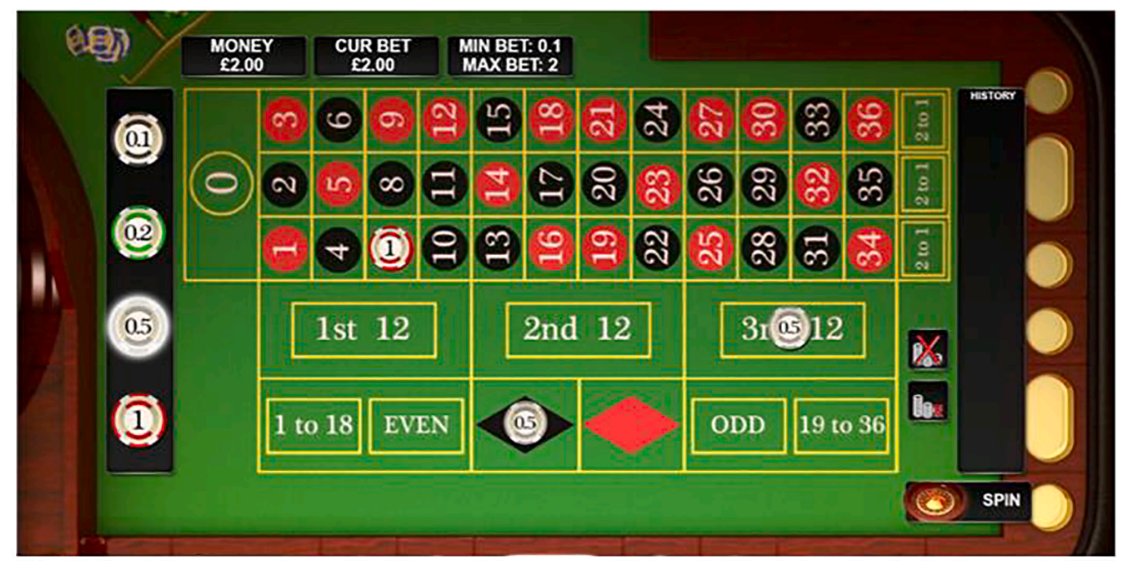

B)

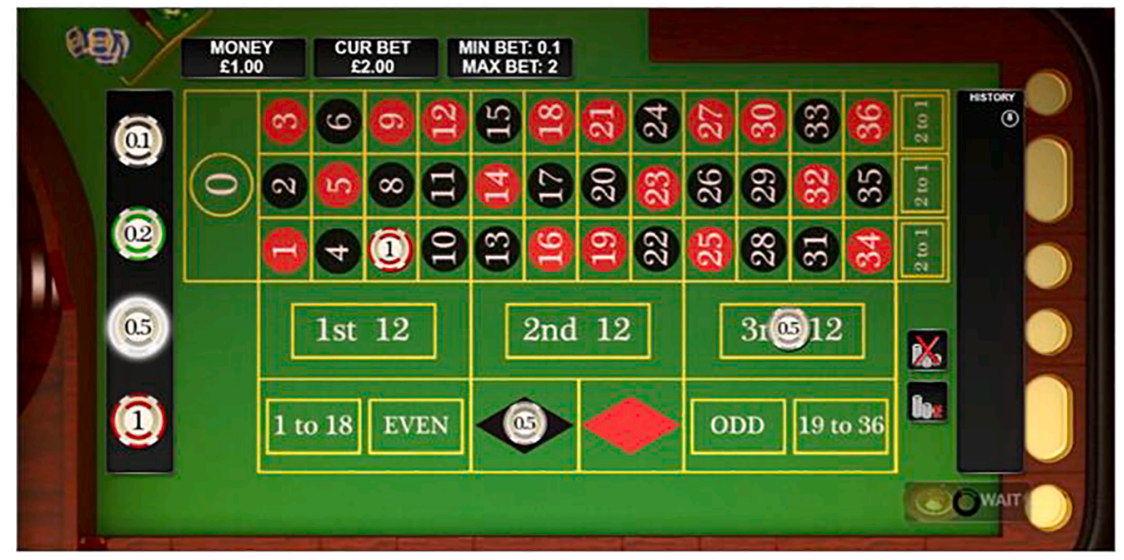

C)

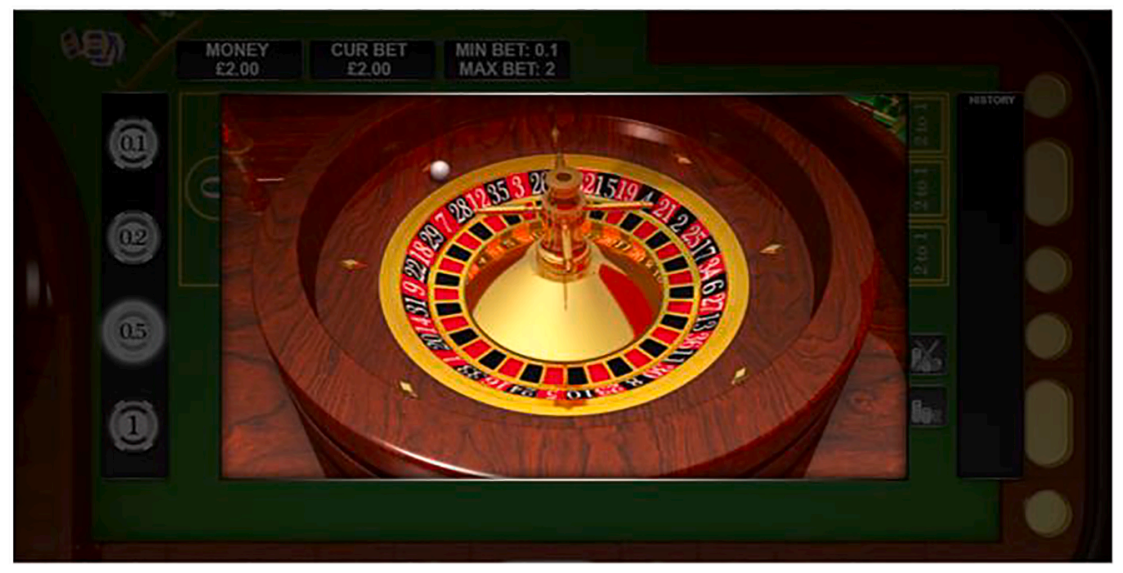

Fig. 2. Screenshots of the roulette game (A) in the normal speed control condition; (B) in the slowed-down condition; and (C) the spinning roulette. The screenshots show the spin button that appeared after a bet was placed on the table. The slowed-down-condition screenshot shows the timer enforcing a 60 -second waiting period. The animated spinning roulette appeared after participants clicked the spin button.

Bayesian estimation is known to be more numerically stable - that is, produce fewer convergence problems - than frequentist estimation (Liu \& Eugenio, 2018). All models were estimated using Stan version 2.21.2 (Carpenter et al., 2017) via the brms package version 2.16.1 (Bürkner, 2017) for the statistical programming language $R$ version 4.1.0 ( $R$ Core Team, 2020). Estimation was performed using Markov Chain Monte Carlo (MCMC) sampling (Van Ravenzwaaij, Cassey, \& Brown, 2018), the preferred way to estimate models in a Bayesian framework. To ensure robust results, all models were estimated with four independent MCMC chains retaining 25,000 post-warmup samples per chain resulting in a total of 100,000 post-warmup samples for analysis. This large number of posterior samples ensured robustness of the results even for the tails of the posterior distribution. In line with this, visual checks as well as the $\widehat{R}$-statistics (all $\widehat{R}<1.001$ ) indicated that all models converged successfully to the stationary distribution. In sum, our approach ensured that we did not encounter any convergence or numerical problems during model estimation.

\section{Results}

The manipulation was successful in slowing down speed-of-play. In the normal speed condition, the average time between two spins (including the time for the wheel to spin) was $21.0 \mathrm{~s}$ (median $=15.0, \mathrm{SD}$ $=25.7$ ). In the slowed-down condition, the average time between spins was $88.6 \mathrm{~s}$ (median $=68.0, \mathrm{SD}=144.6)$. 


\subsection{Proportion bet}

Overall, $19.2 \%$ of participants took the $£ 4$ endowment without gambling on the roulette. Of those who gambled, $14.4 \%$ bet everything and lost their entire endowment. Of the remaining participants who gambled but did not bet everything, the mean proportion bet was $39.9 \%$.

The speed-of-play limit's effect on gambling behavior is summarized in Fig. 3. The top row shows the per-condition estimated averages and associated uncertainties (i.e., the posterior distributions) for the main hypothesis's measures. The bottom row shows how much less likely (percentages less than $0 \%$ on the $\mathrm{x}$-axis) participants were to gamble in the slowed-down condition than the normal speed condition (i.e., the bottom shows the difference distributions of the posterior distributions). There were no credible differences between the conditions in participants' probability to gamble at all, mean $=0.4 \%$, 95\% Bayesian $\mathrm{CI}=$ $[-4.4 \%, 5.4 \%]$. Because there was no functional difference between the roulette game on the first spin across both conditions (i.e., the speed-ofplay limit was only enforced from the second spin onwards), this lack of a difference is not too surprising.

For the "probability to gamble everything" there was a more noticeable difference in the predicted direction. Participants were on average $4.3 \%$ less likely to gamble everything (assuming they placed at least one bet) in the slowed-down condition. However, the evidence for this difference did not reach a credible threshold: $95 \%$ Bayesian $\mathrm{CI}=$ $[-9.2 \%, 0.5 \%]$.

Finally, for the proportion bet there is a credible difference in the predicted direction. The speed-of-play limit reduced the proportion bet for all other participants by an average of $4.0 \%$. For this difference, the evidence reaches a credible threshold: $95 \%$ Bayesian CI $=[-7 \%$, $-0.6 \%]$. In sum, although the speed limit did not affect the proportion of participants betting at least once, it may have somewhat reduced the proportion betting everything, and there is credible evidence that it reduced the total proportion of money bet amongst the remaining participants.

The speed-of-play manipulation's effect on all three dependent measures can be combined into a measure of the unconditional proportion bet. Although this analysis was not preregistered, it can provide a summary measure across all three dependent measures. Participants bet on average $41.7 \%$ of everything that they could in the normal condition (95\% Bayesian CI $=[38.8 \%, 44.6 \%]$ ), and there is credible evidence that this was higher than the $37.1 \%$ bet in the slowed-down condition (95\% Bayesian CI $=[34.3 \%, 39.8 \%]$ ).

\subsection{Number of spins}

Fig. 4 shows the results from the analysis of the number of spins per condition, for participants who bet at least once. The left panel shows the estimated average number of spins per condition and suggests that participants in the slowed-down condition, mean $=1.3,95 \%$ Bayesian $\mathrm{CI}=[1.4,4.2]$, bet on average on fewer spins than participants in the normal speed condition, mean $=2.9,95 \%$ Bayesian $\mathrm{CI}=[0.6,1.9]$. This credible difference is further supported by the difference distribution (right panel) showing a mean difference of -1.6 spins, 95\% Bayesian CI $=[-2.5,-0.7]$. There is credible evidence that the introduction of a speed-of-play limit reduces the average number of spins bet by participants.

\subsection{Average bet size}

Fig. 5 shows the results from the analysis of the average bet sizes, for participants who bet at least once. The leftmost panel shows the average bet size for those participants that did not always bet the maximum of $£ 2$ as a proportion of the maximum bet size, the center panel shows the estimated probability to always bet the maximum bet size, and the two vertical panels on the right show the corresponding difference distributions. As can be seen, there was a small increase in the slowed-down condition for both measures. However, the difference distributions on the right side include 0 in both cases, indicating that the strength of the difference does not pass a credible threshold. For the mean bet size, the estimated difference was $1.4 \%, 95 \%$ Bayesian $\mathrm{CI}=[-1.9 \%, 4.7 \%]$. For the probability of always betting the maximum, the estimated difference was $2.4 \%, 95 \%$ Bayesian $\mathrm{CI}=[-2.2 \%, 6.9 \%]$. The model-predicted mean bet sizes were $£ 0.89(95 \% \mathrm{CI}=[0.83,0.95])$ in the normal condition and $£ 0.94(95 \% \mathrm{CI}=[0.89,1.00])$ in the slowed-down condition. The speedof-play limit may increase the average bet size slightly, but it did not do so here credibly.
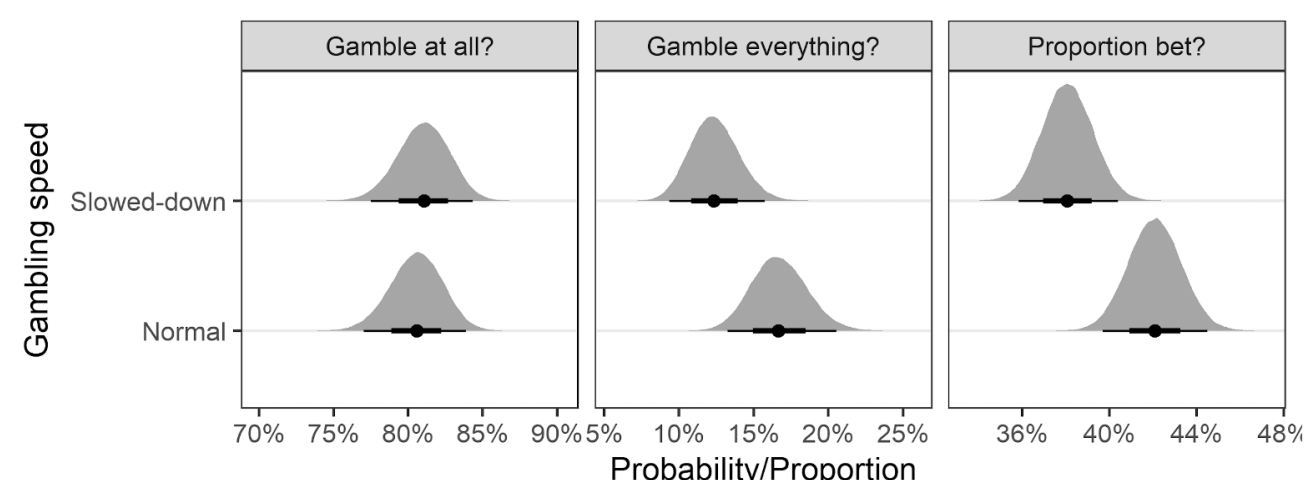

Probability/Proportion
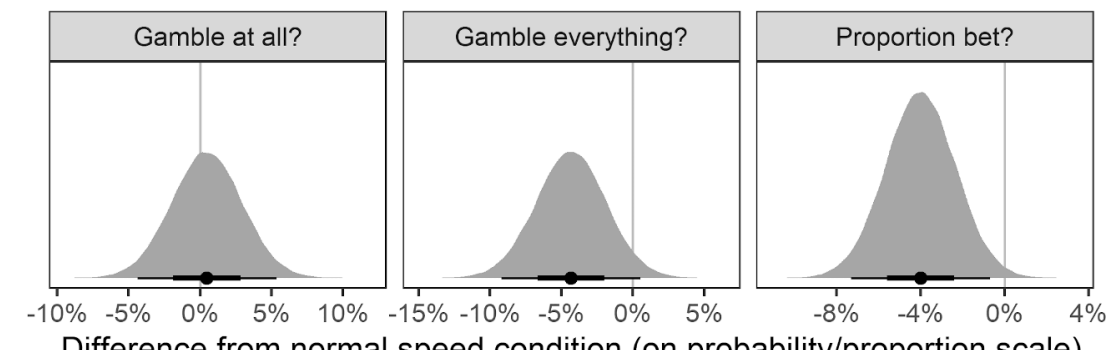

Fig. 3. Top row shows the by-condition posterior distribution of the ZOIBR model on the three measures of proportion bet. The bottom row shows the corresponding difference distributions comparing participants' probability of gambling in the slowed-down condition and in the normal speed control condition. The thin horizontal black lines represent the $95 \%$ credibility intervals, and the thick horizontal black lines represent $66 \%$ credibility intervals. A $95 \%$ credibility interval fully below $0 \%$ on the bottom row provides evidence in the hypothesized direction. 

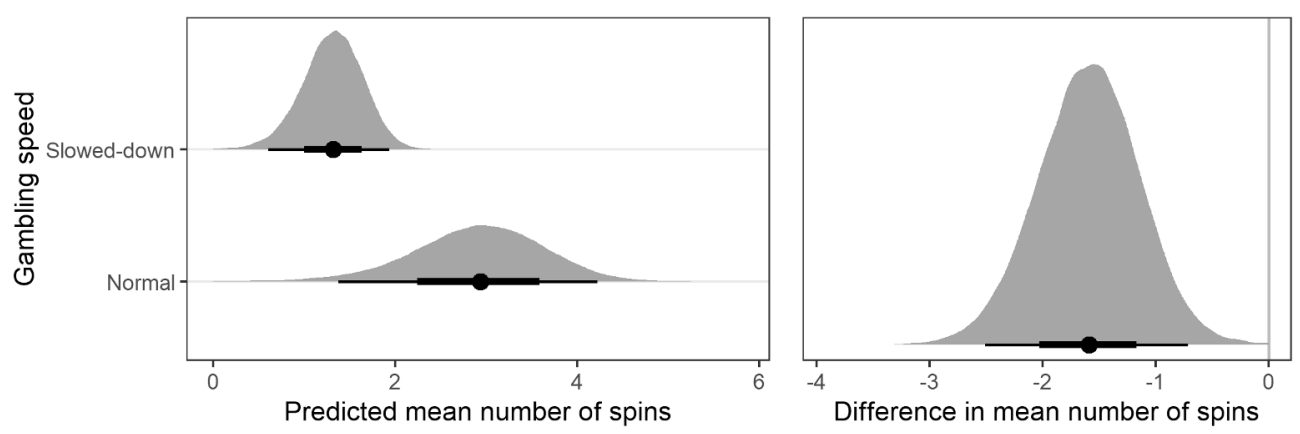

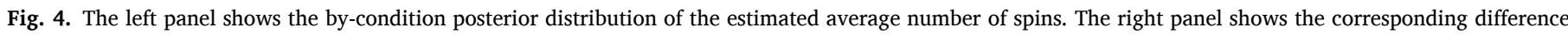
distribution which provides strong evidence for a difference as the difference distribution does not contain 0 .

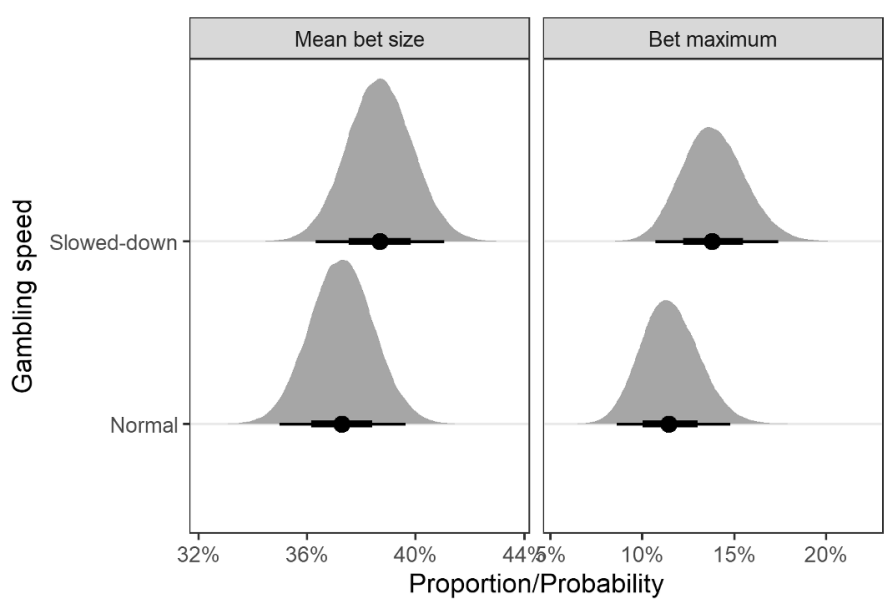

\subsection{Exploratory analyses}

Some additional analyses were conducted for exploratory purposes (details of all results reported in this paper are provided here: htt ps://osf.io/bavq9/). First, some roulette bets are riskier than others, as a $£ 1$ bet on red could win $£ 2$, whereas a $£ 1$ bet on a single number could win $£ 36$. However, an exploratory analysis indicated that the manipulation had no effect on the average riskiness of bets chosen.

Problem gambling has been linked to deficits in impulsiveness (Amlung, Vedelago, Acker, Balodis, \& MacKillop, 2017; Ring et al., 2021), so additional analyses were conducted with PGSI. All main analyses were repeated including PGSI scores as a covariate in the model. Each analysis was repeated twice, once when adding the PGSI scores as an additive main effect, and a second time by adding the (centered) PGSI scores both as a main effect and an interaction with condition. The results of these analyses were numerically very similar to the results reported here, and the inferential pattern for the condition effect (i.e., whether a 95\% Bayesian CI included zero or not) were identical whether or not PGSI was included. Additionally, PGSI scores were positively related with gambling behavior (i.e., the $95 \%$ Bayesian CIs of the relationships did not include zero) across both conditions, regardless of any speed-of-play restriction. In the model in which PGSI was entered as a main effect only, participants that had higher PGSI scores were more likely to gamble at all, were more likely to gamble everything, and bet a larger proportion of remaining funds. None of the interaction models suggested credible interactions of the speed-of-play manipulation with participants' PGSI scores. Crucially, this meant that the speed-of-play manipulation's effect on gambling behavior was not dependent on PGSI scores.

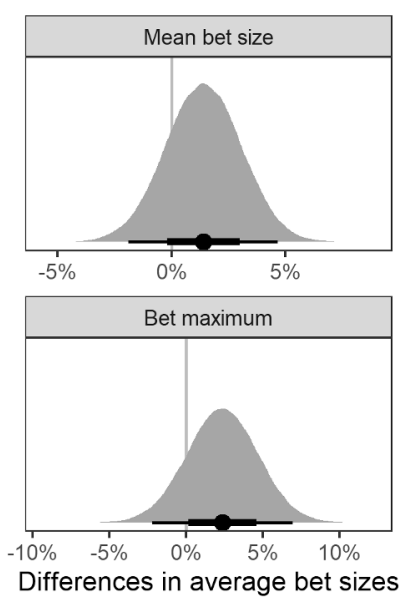

Fig. 5. The two left panels show the bycondition posterior distribution of the estimated averages of the two measures of average bet size (left shows mean bet size as proportion of maximum bet size, and right shows probability to always bet the maximum bet size of $£ 2$ ). The two vertically arranged panels on the right show the corresponding difference distributions. Even though participants in the slowed-down version bet more on average descriptively, both difference distributions contain 0 indicating that the evidence for this difference is weak.

\section{Discussion}

The present work's results show that the speed-of-play limit led to a credible reduction in the proportion of money bet, due to a credible reduction in the mean number of spins outweighing any potential increases in bet sizes. This reduction in the proportion of money bet occurred despite participants spending more time playing the roulette game in the slowed-down condition, as the three-fold increase in bet times was higher than the halving in number of bets.

\subsection{Policy implications: current evidence and future directions}

Stake and speed-of-play limits are two alterations to the structural characteristics of online casino games that may help to lessen gamblers' expenditure (Cornish, 1978; Landon et al., 2018; Livingstone et al., 2008). Importantly, whereas stake limits may serve to primarily reduce expenditure amongst high-spending gamblers, speed-of-play limits may serve to additionally reduce expenditure across all gamblers. This is important given that $78 \%$ of online casino sessions result in the gambler winning or losing $£ 20$ or less, and that online casino spending is higher in the most-deprived areas of the UK compared to the least-deprived (Forrest \& McHale, 2021). This population-level benefit of speed-ofplay limits may be one of the most important benefits of using this intervention as part of a suite of harm reduction interventions: The reduction of overall proportion bet from $41.7 \%$ to $37.1 \%$ was statistically credible, but leaves room for other interventions to reduce gambling expenditure further.

One limitation of the current evidence base for policy decisions on speed-of-play is the reliance on laboratory (either in-person or online) results, with field studies being rare (Blaszczynski et al., 2005; Sharpe et al., 2005). Therefore, a field study run in collaboration with an online 
operator, where online gamblers are gambling with their own money naturalistically, would provide so-called "gold standard" evidence. Similar field studies have been run previously to test other consumer protection measures, in collaboration with the Norwegian state-owned operator (Jonsson, Hodgins, Munck, \& Carlbring, 2020), with Australian online wagering operators (Heirene \& Gainsbury, 2021), and with a UK online operator (Behavioural Insights Team, 2021). However, we note that the presence of gold standard evidence has not always been sufficient to motivate operators to implement safer gambling innovations. A field study published in early 2021 showed how deposit limit setting tools could be designed to nudge deposit limits over $40 \%$ lower than existing tools (Behavioural Insights Team, 2021). Yet at the present time of writing, the operator who collaborated on this tool has not updated their deposit limit setting tool in light of these findings (Newall \& Rockloff, 2021).

\subsection{Limitations}

The present research has strengths including its dual-task structure, use of a commercial online roulette game, large sample size, and preregistered analysis plan. However, like any research, it has weaknesses too. The research used only one commercial online casino game and one speed-of-play limit; different games and speeds may yield different results. The research used a stake limit of $£ 2$, consistent with the current stake limit on UK EGMs, whereas UK online casino games are not currently subject to any stake limits. Different results may occur if speedof-play limits are implemented without any limitations on stakes. Different results may also occur when gamblers bet with their own money in naturalistic online environments. Most participants engaged with the online roulette game for a relatively short amount of time. Although short gambling sessions make up the majority of actual online casino sessions, with "long sessions represent[ing] an atypical behaviour" (Forrest \& McHale, 2021), these results are less likely to apply, for example, to the $2 \%$ of online casino sessions lasting two hours or longer (Forrest \& McHale, 2021). Importantly, the experiment was limited with respect to the backfire effects that could be detected. Participants in the slowed-down condition may have quit gambling if they intended to use their payment rewards to gamble on normal commercial online roulette games (all payments were made after data collection ceased in order to reduce this possibility). Other backfire effects are possible in realistic online gambling environments. Gamblers could switch to other and potentially more-harmful gambling games in response to any restrictions on specific games. Gamblers may open multiple simultaneous online casino games, either on a single operator's platform or across multiple operators. Online poker players, for example, are well known to "multi-table," to further increase the speed of online poker play in comparison to casino poker (Hopley, Dempsey, \& Nicki, 2012), and similar moves could be incentivized by novel online casino design features (Newall, 2019; Schüll, 2012).

There are different ways that speed-of-play limits could be graphically implemented, and for example a visual timer counting-down to zero may lead to different behavior than the "wait" button implemented here, given that the mean speed-of-play was $88.6 \mathrm{~s}$. Future research should investigate the effect of different timer implementations, as well as gambler experiences and enjoyment while playing.

\subsection{Conclusions}

Numerous UK policy-makers are proposing changes to the online gambling landscape (House of Lords, 2020; Noyes \& Shepherd, 2020; Public Accounts Committee, 2020), and other jurisdictions are also considering their regulation of online gambling, with many US states currently increasing the availability of online gambling (Jones, 2021). The present research shows how speed-of-play limits for online roulette may be effective in reducing gambling expenditure, and how any policy changes can be informed by online experimental research.

\section{CRediT authorship contribution statement}

Philip W.S. Newall: Conceptualization, Data curation, Formal analysis, Investigation, Writing - original draft. Leonardo WeissCohen: Methodology, Writing - review \& editing. Henrik Singmann: Methodology, Writing - review \& editing. W. Paul Boyce: Methodology, Writing - review \& editing. Lukasz Walasek: Methodology, Writing review \& editing. Matthew J. Rockloff: Funding acquisition, Writing review \& editing, Supervision.

\section{Declaration of Competing Interest}

The authors declare the following financial interests which may be considered as potential competing interests: Philip Newall is a member of the Advisory Board for Safer Gambling - an advisory group of the Gambling Commission in Great Britain, and in 2020 was a special advisor to the House of Lords Select Committee Enquiry on the Social and Economic Impact of the Gambling Industry. In the last three years Philip Newall has received research funding from Clean Up Gambling, and has contributed to research projects funded by GambleAware, Gambling Research Australia, NSW Responsible Gambling Fund, and the Victorian Responsible Gambling Foundation. In 2019 Philip Newall received travel and accommodation funding from the Spanish Federation of Rehabilitated Gamblers, and in 2020 received an open access fee grant from Gambling Research Exchange Ontario. Matthew Rockloff has received research funds from Gambling Research Australia, Victorian Responsible Gambling Foundation, Queensland Treasury, Victorian Treasury, NSW Responsible Gambling Fund, NSW Office of Liquor \& Gaming, Tasmanian Department of Treasury and Finance, New Zealand Ministry of Health, Department of Families, Housing, Community Services and Indigenous Affairs, Alberta Gambling Research Institute and the First Nations Foundation. He declares no conflicts of interest in relation to this manuscript. The other authors have no interests to declare.

\section{References}

Allami, Y., Hodgins, D. C., Young, M., Brunelle, N., Currie, S., Dufour, M., ... Nadeau, L. (2021). A meta-analysis of problem gambling risk factors in the general adult population. Addiction. https://doi.org/10.1111/add.15449

Amlung, M., Vedelago, L., Acker, J., Balodis, I., \& MacKillop, J. (2017). Steep delay discounting and addictive behavior: A meta-analysis of continuous associations. Addiction, 112(1), 51-62.

Armstrong, T., Rockloff, M., \& Donaldson, P. (2016). Crimping the croupier: Electronic and mechanical automation of table, community and novelty games in Australia. Journal of Gambling Issues, 33, 103-123.

Armstrong, T., Rockloff, M., Greer, N., \& Donaldson, P. (2017). Rise of the machines: A critical review on the behavioural effects of automating traditional gambling games. Journal of Gambling Studies, 33(3), 735-767.

Behavioural Insights Team. (2021). Applying behavioural insights to design safer gambling tools. part 1: Anchoring. Retrieved from https://www.bi.team/ publications/applying-behavioural-insights-to-design-safer-gambling-tools/.

Blaszczynski, A., Sharpe, L., Walker, M., Shannon, K., \& Coughlan, M. (2005). Structural characteristics of electronic gaming machines and satisfaction of play among recreational and problem gamblers. International Gambling Studies, 5(2), 187-198.

Browne, M., Langham, E., Rawat, V., Greer, N., Li, E., Rose, J., ... Best, T. (2016). Assessing gambling-related harm in victoria: A public health perspective. Melbourne: Victorian Responsible Gambling Foundation.

Bürkner, P. (2017). Brms: An R package for bayesian multilevel models using stan. Journal of Statistical Software, 80(1), 1-28.

Byrne, C., \& Russell, A. (2020). Making EGMs accountable: Can an informative and dynamic interface help players self-regulate. Journal of Gambling Studies, 36, 1229-1251.

Carpenter, B., Gelman, A., Hoffman, M. D., Lee, D., Goodrich, B., Betancourt, M., Riddell, A. (2017). Stan: A probabilistic programming language. Journal of Statistical Software, 76(1), 1-32.

Chóliz, M. (2010). Experimental analysis of the game in pathological gamblers: Effect of the immediacy of the reward in slot machines. Journal of Gambling Studies, 26(2), 249-256.

Codecanyon. (n.d.). Https://Codecanyon.net/item/roulette-royale-html5-casino-game/ 17072843. Retrieved from https://codecanyon.net/item/roulette-royale-html5casino-game/17072843.

Cohen, J. (1992). A power primer. Psychological Bulletin, 112(1), 155-159.

Cornish, D. B. (1978). Gambling: A review of the literature and its implications for policy and research. London: Her Majesty's Stationery Office. 
Corr, P. J., \& Thompson, S. J. (2014). Pause for thought: Response perseveration and personality in gambling. Journal of Gambling Studies, 30(4), 889-900.

Currie, S. R., Hodgins, D. C., \& Casey, D. M. (2013). Validity of the problem gambling severity index interpretive categories. Journal of Gambling Studies, 29(2), 311-327.

Delfabbro, P., Falzon, K., \& Ingram, T. (2005). The effects of parameter variations in electronic gambling simulations: Results of a laboratory-based pilot investigation. Gambling Research: Journal of the National Association for Gambling Studies (Australia), 17(1), 7-25.

Dixon, M. J., Stange, M., Larche, C. J., Graydon, C., Fugelsang, J. A., \& Harrigan, K. A. (2018). Dark flow, depression and multiline slot machine play. Journal of Gambling Studies, 34(1), 73-84.

Downton, F., \& Holder, R. L. (1972). Banker's games and the gaming act 1968. Journal of the Royal Statistical Society. Series A (General), 135(3), 336-364.

Erkal, N., Gangadharan, L., \& Nikiforakis, N. (2011). Relative earnings and giving in a real-effort experiment. American Economic Review, 101(7), 3330-3348.

Ferris, J., \& Wynne, H. J. (2001). The canadian problem gambling index: Final report. Ottawa, ON: Canadian Centre on Substance Abuse.

Forrest, D., \& McHale, I. (2021). Exploring online patterns of play. interim report. Retrieved from https://www.begambleaware.org/sites/default/files/2021-03/PoP Interim\%20Report_Short_Final.pdf.

Gambling Commission. (2018). Review of online gambling. Retrieved from https:// assets.ctfassets.net/j16ev64qyf6l/mJ7A1C5buMifnkm2vTdEy/ 8fd73cbfb38ba4dd09c7e8134ef92566/Online-review-March-2018.pdf.

Gambling Commission. (2021). Gambling commission announces package of changes which make online games safer by design. Retrieved from https://www. gamblingcommission.gov.uk/news-action-and-statistics/news/2021/GamblingCommission-announces-package-of-changes-which-make-online-games-safer-bydesign.aspx.

Gambling Related Harm All Party Parliamentary Group. (2020). Online gambling harm inquiry. Final report. Retrieved from http://www.grh-appg.com/wp-content/ uploads/2020/12/Online-report-Final-June162020.pdf.

Grochowski, J. (2021). How to play roulette. Retrieved from https://web.archive.org/ web/20201027185851/https://entertainment.howstuffworks.com/how-to-playroulette.htm.

Harrigan, K., MacLaren, V., Brown, D., Dixon, M. J., \& Livingstone, C. (2014). Games of chance or masters of illusion: Multiline slots design may promote cognitive distortions. International Gambling Studies, 14(2), 301-317.

Harris, A., Gous, G., de Wet, B., \& Griffiths, M. D. (2021). The relationship between gambling event frequency, motor response inhibition, arousal, and dissociative experience. Journal of Gambling Studies, 37, 241-268. https://doi.org/10.1007/ s10899-020-09955-0

Harris, A., \& Griffiths, M. D. (2018). The impact of speed of play in gambling on psychological and behavioural factors: A critical review. Journal of Gambling Studies, 34(2), 393-412.

Heirene, R. M., \& Gainsbury, S. M. (2021). Encouraging and evaluating limit-setting among on-line gamblers: A naturalistic randomized controlled trial. Addiction. https://doi.org/10.1111/add.15471

Hopley, A. A., Dempsey, K., \& Nicki, R. (2012). Texas hold'em online poker: A further examination. International Journal of Mental Health and Addiction, 10(4), 563-572.

House of Lords. (2020). Select committee on the social and economic impact of the gambling industry. gambling harm - time for action. Retrieved from https:// publications.parliament.uk/pa/ld5801/ldselect/ldgamb/79/79.pdf.

Jones, Z. (2021). Rise of the IGaming industry: Is the united states ready to accept online casinos?. Retrieved from https://www.forbes.com/sites/zackjones/2021/04/21/the -rise-of-the-igaming-industry-what-is-in-store-for-the-citizens-of-united-states/.

Jonsson, J., Hodgins, D. C., Munck, I., \& Carlbring, P. (2020). Reaching out to big losers leads to sustained reductions in gambling over 1 year: A randomized controlled trial of brief motivational contact. Addiction, 115(8), 1522-1531.

Kilby, J., Fox, J., \& Lucas, A. F. (2004). Casino operations management (2nd ed.). Wiley.

Ladouceur, R., \& Sevigny, S. (2006). The impact of video lottery game speed on gamblers. Journal of Gambling Issues (17).

Landon, J., du Preez, K. P., Page, A., Bellringer, M., Roberts, A., \& Abbott, M. (2018). Electronic gaming machine characteristics: It's the little things that count. International Journal of Mental Health and Addiction, 16(2), 251-265.

Lawn, S., Oster, C., Riley, B., Smith, D., Baigent, M., \& Rahamathulla, M. (2020). A literature review and gap analysis of emerging technologies and new trends in gambling. International Journal of Environmental Research and Public Health, 17(3), 744.

Linnet, J., Rømer Thomsen, K., Møller, A., \& Callesen, M. B. (2010). Event frequency, excitement and desire to gamble, among pathological gamblers. International Gambling Studies, 10(2), 177-188.
Liu, F., \& Eugenio, E. C. (2018). A review and comparison of bayesian and likelihoodbased inferences in beta regression and zero-or-one-inflated beta regression. Statistical Methods in Medical Research, 27(4), 1024-1044.

Livingstone, C., Woolley, R., Zazryn, T. R., Bakacs, L., \& Shami, R. G. (2008). The relevance and role of gaming machine games and game features on the play of problem gamblers Independent Gambling Authority.

Loba, P., Stewart, S. H., Klein, R. M., \& Blackburn, J. R. (2001). Manipulations of the features of standard video lottery terminal (VLT) games: Effects in pathological and non-pathological gamblers. Journal of Gambling Studies, 17(4), 297-320.

Markham, F., Young, M., \& Doran, B. (2016). The relationship between player losses and gambling-related harm: Evidence from nationally representative cross-sectional surveys in four countries. Addiction, 111(2), 320-330.

Mentzoni, R. A., Laberg, J. C., Brunborg, G. S., Molde, H., \& Pallesen, S. (2012). Tempo in electronic gaming machines affects behavior among at-risk gamblers. Journal of Behavioral Addictions, 1(3), 135-139.

Muggleton, N., Parpart, P., Newall, P., Leake, D., Gathergood, J., \& Stewart, N. (2021). The association between gambling and financial, social, and health outcomes in big financial data. Nature Human Behaviour, 5, 319-326. https://doi.org/10.1038/ s41562-020-01045-w

Newall, P. W. S., Weiss-Cohen, L., Singmann, H., Walasek, L. \& Ludvig, E. A. (2021). No credible evidence that UK safer gambling messages reduce gambling. Retrieved from https://psyarxiv.com/hv6w9.

Newall, P. W. S. (2019). Dark nudges in gambling. Addiction Research \& Theory, 27(2), 65-67. https://doi.org/10.1080/16066359.2018.1474206

Newall, P. W. S., \& Rockloff, M. J. (2021). Promoting safer gambling via the removal of harmful sludge: A view on how behavioral science's "nudge" concept relates to online gambling. Addiction. https://doi.org/10.1111/ADD.15700

Noyes, J., \& Shepherd, J. (2020). Gambling review and reform: Towards a new regulatory framework. Retrieved from https://www.smf.co.uk/wp-content/ uploads/2020/08/Gambling-review-and-reform-August-2020.pdf.

Oldman, D. (1974). Chance and skill: A study of roulette. Sociology, 8(3), 407-426.

Pickering, D., \& Blaszczynski, A. (2021). Paid online convenience samples in gambling studies: Questionable data quality. International Gambling Studies. https://doi.org/ 10.1080/14459795.2021.1884735

Public Accounts Committee. (2020). Gambling regulation: Problem gambling and protecting vulnerable people. Retrieved from https://publications.parliament.uk/ $\mathrm{pa} / \mathrm{cm} 5801 / \mathrm{cmselect} / \mathrm{cmpubacc} / 134 / 13402 . \mathrm{htm}$.

R Core Team. (2020). R: A language and environment for statistical computing. Retrieved from https://www.R-project.org/.

Ring, P., Probst, C., Neyse, L., Wolff, S., Kaernbach, C., van Eimeren, T., \& Schmidt, U. (2021). Discounting behavior in problem gambling. Journal of Gambling Studies. https://doi.org/10.1007/s10899-021-10054-x

Rockloff, M. J., Donaldson, P., \& Browne, M. (2015). Jackpot expiry: An experimental investigation of a new EGM player-protection feature. Journal of Gambling Studies, 31 (4), 1505-1514.

Rossi, R., Nairn, A., Smith, J., \& Inskip, C. (2021). "Get a 10 free bet every week!"-Gambling advertising on twitter: Volume, content, followers, engagement and regulatory compliance. Journal of Public Policy \& Marketing, 1, 18.

Schüll, N. D. (2012). Addiction by design: Machine gambling in las vegas. Princeton, New Jersey: Princeton University Press.

Sharpe, L., Walker, M., Coughlan, M., Enersen, K., \& Blaszczynski, A. (2005). Structural changes to electronic gaming machines as effective harm minimization strategies for non-problem and problem gamblers. Journal of Gambling Studies, 21(4), 503-520.

Thompson, S. J., \& Corr, P. J. (2013). A feedback-response pause normalises response perseveration deficits in pathological gamblers. International Journal of Mental Health and Addiction, 11(5), 601-610.

van de Schoot, R., Depaoli, S., King, R., Kramer, B., Märtens, K., Tadesse, M. G., Willemsen, J. (2021). Bayesian statistics and modelling. Nature Reviews Methods Primers, 1(1), 1-26.

Van Ravenzwaaij, D., Cassey, P., \& Brown, S. D. (2018). A simple introduction to markov chain Monte-Carlo sampling. Psychonomic Bulletin \& Review, 25(1), 143-154.

Witherow, T. (2020). Cash lost to betting machines fell by nearly HALF last year following the introduction of a $£ 2$ maximum stake. Retrieved from https://www. dailymail.co.uk/news/article-8371461/Cash-lost-betting-machines-fell-nearlyHALF-year.html.

Wohl, M. J., Davis, C. G., \& Hollingshead, S. J. (2017). How much have you won or lost? personalized behavioral feedback about gambling expenditures regulates play. Computers in Human Behavior, 70, 437-445.

Worhunsky, P. D., \& Rogers, R. D. (2018). An initial investigation of individual rate-ofplay preferences and associations with EGM gambling behavior. Journal of Gambling Studies, 34(4), 1067-1083. 